\title{
Should Lecturers be willing to Teach High-functioning Autistic Students: What do They Need to Know?
}

\author{
E. Ponomaryova ${ }^{1}$, Dr. H. Gendel Guterman ${ }^{2}$, Prof. N. Davidovitch ${ }^{2} \&$ Prof. Y. Shapira $^{3}$ \\ ${ }^{1}$ Post graduate student, Ariel University, Israel \\ ${ }^{2}$ The Faculty of Social Sciences, Ariel University, Israel \\ ${ }^{3}$ The Faculty of Health Sciences, Ariel University, Israel \\ Correspondence: N. Davidovitch, The Faculty of Social Sciences, Ariel University, Israel. E-mail: \\ d.nitza@ariel.ac.il
}

Received: July 15, 2018

Accepted: August 2, $2018 \quad$ Online Published: September 5, 2018

doi:10.5539/hes.v8n4p35

URL: https://doi.org/10.5539/hes.v8n4p35

\begin{abstract}
Academic institutions are currently developing special programs based on the belief that the overall success of universities relies on the integration of diverse population groups. This study investigates the role of the organizational support to lecturers to facilitate the integration of students with high-functioning autism (HFA). A questionnaire was developed and completed by 103 lecturers to examine their attitudes on the best methods for integrating students with HFA in higher education. Both regression and path analysis were performed. The findings show that the university's support is the main factor that influences instructors' beliefs on the best method of integration, either by creating a tolerant atmosphere in the institution or using specially developed teaching methods. Lecturers' positive emotional responses and desire to be familiar with and involved with HFA students influence lecturers' ability to provide effective support to students with HFA.
\end{abstract}

Keywords: organizational support, high-functioning autism, higher education, integration

\section{Introduction}

In recent years, the State of Israel has been undergoing a change in its attitude toward individuals with autism spectrum disorder (Avisar, 2010). This change is primarily manifest in the recognition of these individuals' basic right to a full, productive life, a life of self-realization, and not a life on the margins, outside, but rather their integration into all areas of human endeavor, as part of the right to education and maximum integration in the community and society. Therefore, the community integration and participation in societal life are fundamental values of the highest importance (Officer \& Groce, 2009; Ward \& Stewart, 2008). A significant expression of this trend is the Equal Rights for People with Disabilities Law 5758-1998, a law that defines the rights of individuals with disabilities and the obligations of Israeli society to protect these rights.

Similar changes have occurred in most developed countries worldwide in recent decades (Avisar, 2010). A reflection of this trend is the Convention on the Rights of Persons with Disabiliti4es (CRPD), which was adopted by the UN in 2007. Israel ratified the CRPD in September 2012, but in practice included its principles in the Equal Rights for People with Disabilities Law (Ministry of Education website).

Higher education is an essential instrument of social development, and of developing and transmitting formative knowledge. As a key to individual integration in society and in the workplace, the accessibility of the higher education system in Israel is of enormous importance (Avisar, 2010). Creating an accessible campus for students, lecturers, employees, and visitors depends not only on entry, orientation, and navigation on campus, but also a complete egalitarian right to the totality of services that the campus offers. Usually academic institutions offer a variety of services and human support that create access to and facilitate the maximal integration of individuals into student life (Avisar, 2010).

The basis of the current study is a case study at Ariel University, which provides support to address the needs of students with autism spectrum disorder, and help them reach their full potential (Program for Integration of High-Functioning Students with Autism, 2014). The project was initiated in 2008 with two students and currently includes 47 students. Similarly, to other efforts to enhance accessibility for special needs populations and students with disabilities, the goal of the Program is to create equal opportunities to acquire a higher 
education, create accessibility to learning and social integration, and help acquire tools and skills for independent coping (Program for Integration of High-Functioning Students with Autism, 2014). The project also serves as a model for other academic institutions in Israel that strive to enhance the adjustment and integration of students with autism spectrum disorder.

This study examines the influence of the described university organizational support for integration on the lecturers' level (Ponomareva, Davidovitch, \& Shapira, 2016). We believe that the organizational support is the factor that has the strongest influence on lecturers' willingness to use a special developed method, or to achieve a tolerant atmosphere in class, for the integration of students with HFA in academic studies.

As found in previous research, there are additional relevant variables for integration, which are included in this study: familiarity with HFA, lecturers' involvement, "emotional response" to students with HFA, and regular teaching methods to regular students.

As noted, in our study we focused on the teaching staff's attitudes on the integration of students with HFA in academic studies in Israel. The study may also have practical implications for policymakers, lecturers, and teaching methods in higher education. Some issues are, for example: for policymakers in higher education - the question is whether academic excellence and equal opportunities can go hand in hand; for lecturers - the question is how and to what extent academic teaching should be adapted to special needs populations. Should lecturers help create a classroom tolerant atmosphere that might help students with HFA? And how can lecturers help create a climate of support and self-efficacy that might help students with HFA?

\subsection{Autism Spectrum Disorder (HFA)}

Autism is a developmental neurological disorder that appears as early as the age of 18-36 months (Narasingharao, Pradhan, \& Navaneetham, 2017). The disorder is characterized by broad and severe challenges with three areas of development: social, communications, and behavioural functioning (Delfos, 2005).

The impact on communications and social functioning is caused by defects in establishing communications or a deficit in social communications. Disordered interactions that are expressed in the use of inappropriate words at inappropriate times, difficulty in maintaining eye contact (Narasingharao, Pradhan, \& Navaneetham, 2017), difficulties in receiving messages from others and developing mutual relations (Delfos, 2005). Behavioral disorders include repetitive behaviors, aggressive behaviors, irritability, non-compliance, and self-harm. Moreover, other traits include problems with sensory integration, motor problems, anxiety, depression, and language problems. It is therefore unsurprising that individuals with HFA also suffer from various learning disorders (Narasingharao, Pradhan, \& Navaneetham, 2017). The autism spectrum is very broad - and the scale may range from close to normal to very severe. In this study, we focus on students with high-functioning autism who attend higher education. Typically, these students have problems and disabilities in the areas of interpersonal communications, interactions, social adjustment, and imagination; on the other hand, they have normally developed cognitive abilities and adaptive behaviors (excluding social interactions), interest, and curiosity (typically exaggerated and obsessive and focused on a narrow issue or field). High-functioning autism is more prevalent in males than females, at a ratio of 5 to 1 . Prevalence of HFA in the general population is $0.36 \%$ (Volkmar, 2013).

Students with HFA sometimes encounter difficulty in coping with the challenges related to studies and leading an independent life as adults (Palmer, 2006). A person's ability for self-direction based on his or her "inner compass" and the acquisition of relevant skills for functioning in various areas of life is the foundation for creating a meaningful and desired life reality. Paradoxically, the high verbal and cognitive skills of graduates with HFA may be misleading and create an erroneous impression that they have no need for external support or assistance. However, experience from the field and various research findings indicate high levels of loneliness, difficulties in decision making, high dependency on family members, and employment in occupations that are not consistent with or do not express their qualifications (Palmer, 2006). In the absence of a supportive setting in adulthood, professional guidance during higher education studies based on relevant, focused knowledge may be a supportive, guiding factor at such a critical stage in life.

\subsection{Integration of Students with HFA in Higher Education in Israel}

The integration of students with HFA in higher education is of great importance for individuals and for society. For individuals, integration may:

(a) alleviate loneliness and lack of social ties;

(b) provide opportunities to practice and perfect social skills and independence skills; 
(c) provide a normative solution for leisure time;

(d) reduce a general sense of alienation and exclusion;

(e) Obtain knowledge and complete a degree.

Regarding socialization, many of the integration difficulties of students with HFA in society (such as social integration, integration in education, and integration in the labor market) stem from social prejudices and misconceptions. The more students are exposed to students with HFA, the more they develop more tolerant social attitudes and have a more positive impact on the public discourse, both as students and subsequently as adults (Davidovitch, Ponomareva, \& Shapiro, 2017).

Today, most universities that work with individuals with HFA are motivated by a desire to engage in community service. Universities are involved in various degrees in integration of students with HFA and only a small proportion of universities maintain university-wide professional support services (Davidovitch, Schacham, \& Margalit, 2012).

Integration is a psychological concept that concerns the establishment of genuine ties between individuals with special needs and "normal" individuals. In this study, we focus on integration by increasing the participation and involvement of students with HFA in the social and academic life that takes place at the university. In the field of education, integration is usually considered a concept that includes integration, diversity, inclusion, and participation.

Integration is the acceptance of the target culture by the minority group (Berry, 1991). It has been found that integration can succeed only when the minority group desires integration and when the majority is open, supports cultural diversity, and therefore wishes to include the minority group. It has been argued that academic and social integration is a condition for perseverance and has a positive effect on academic achievements (Berry, 1991).

\subsection{Methods for Integrating Students with HFA}

Academic institutions have three functions: teaching, research, and community service (Berry, 1991). Therefore, any discussion on the ways in which students with HFA can be integrated into higher education should address these functions. In the current study, we address the contribution of teaching in a research university to community service.

1. Organizational support and assistance. In the past decade, the need for social-academic integration of students with HFA has come to the attention of the higher education system (The Israeli Society for Autistic Children ALUT - website). The issue began as a local initiative and a project in one academic institution. Today, many academic institutions are embracing these students as part of their policy of community involvement. The Council for Higher Education is also supportive, both in terms of policy decisions and in terms of funding (Ministry of Education website).

Reiter \& Schalock (2008) distinguishes between two worldviews that guide work on integration: (a) the normative approach, which guided integration policy until recently and considers integration as the target of these efforts; and (b) the educational-humanistic quality of life approach - that has developed recently and considers integration as a condition for enhancing quality of life, which is the important goal (Oplatka, 2007; Vaandrager \& Koelen, 2013). Therefore, the transition to a policy based on educational-humanistic principles may enhance the quality of life of students with special needs, both in their integration in educational institutions, and in their integration in the community and its institutions.

In summary, it appears that the academic integration of students with HFA is a positive phenomenon and therefore it is important to examine the attitudes of all students and teaching faculty toward students with HFA in order to encourage their integration in universities (Darling-Hammond \& Bransford, 2007; Lockhorst \& Admiraal, 2012).

2. Teaching and a tolerant atmosphere. Notzer, Zisenwein, and Sarnet (cited in Hativa, 2002), address seven points that represent the approaches and principles that are accepted in higher education teaching, and that correspond to the principles that have traditionally been used in teaching in yeshivas [religious education institutions], in which teaching and social-academic climate is of great value (Davidovitch, 2005).

The learner's self-efficacy beliefs are related to variables and factors connected to the variety of learner traits and modes of learning and to teachers and teaching. Moreover, these beliefs are related to diverse features of the learning environment, which depend on the teaching practices in the organization. For example, students reported having higher abilities when they studied in schools with few disciplinary issues, where pupils were 
high achievers and came from a high socio-economic background. It appears that pupils' high abilities are related to a supportive learning environment and to the degree of involvement: pupils who reported feeling more strongly involved and having the power to affect decisions related to teaching and the curriculum also reported a high sense of abilities (Levinson, 1980).

In addition to the background and cultural features of the school, learners' abilities are also affected by factors related to the nature of the classroom, such as the prestige of the program, the subject. There are five directions that potentially have a positive impact on a learner's sense of ability (Bandura, 1997; Hativa, 2002; Levinson, 1980; Rich, Lev, \& Fischer, 2000). Notably, to our knowledge, these proposals have not yet been systematically evaluated in Israel or worldwide and therefore should be used with caution. The directions of action are:

- Increase collaboration among learners - Several studies (Levinson, 1980) found a connection between learners' self-efficacy and the collaboration that takes place with other learners. It appears that increasing genuine collaboration may have a positive impact on ability through three pathways: through discussions with other learners, the learner may improve his or her own learning skills; acquire new perspectives and insights on the topic; and learn better ways of conducting discussions, writing papers, and presenting them to others.

- Empowering learners - A learner's sense of empowerment depends on his or her perception of the resources that are necessary to promote his or her professional and learning achievements. Genuine, constructive, relevant feedback that emphasizes the learner's positive activities will also strengthen his or her sense of empowerment and self-efficacy.

- Professional and emotional support of learners - Research (Rich, Lev \& Fischer, 2000) has shown that learner' self-efficacy increases following positive feedback by a person of authority in the organization. The caring that teachers and staff show increase learners' self-efficacy, especially in new learners who are as yet unable to base their sense of self-efficacy on their own positive experiences in the organization.

- Preventing harm through external projects - Multiple changes related to new learning methods, tasks, and curricula may impair learners' sense of self-efficacy. Actions that might prevent or moderate the negative effect of external interventions will facilitate and encourage a positive impact, which may increase learners' sense of self-efficacy over time. Organizational activities that offer emotional and professional support to learners in the period of change, and organizational efforts to involve learners in decision-making related to the changes, may act as countervailing forces to the natural decline in their sense of self-efficacy. All learners may be affected by problems related to self-efficacy beliefs, but it is reasonable to assume that some groups of learners have greater resilience and are less vulnerable to these problems. In contrast, other groups of learners may be vulnerable to a decline in their sense of self-efficacy and will require assistance from the organization. Examples of such groups include new immigrants, learners with learning disabilities, learners from a low socio-economic background, and learners with negative learning experiences (Levinson, 1980).

- Tolerant atmosphere - Academic-social climate plays an important role in teaching and learning in all educational settings. This insight has been largely neglected with respect to higher education (Hativa, 2002). When a lecturer is tolerant and understands that the learners in the classroom represent a broad range of needs, the lecturer will make efforts to adjust his or her teaching to the specific group of learners.

In this study, we chose to investigate "tolerant atmosphere" in an academic institution, compared to special teaching methods. Tolerant atmosphere was measured using a classroom environment questionnaire developed by Moos \& Insel (1974). The rationale underlying this questionnaire is that a consensus among individuals regarding the features of an environment constitutes a measure of the socio-academic climate of that environment (Moos \& Insel, 1974).

The contribution of this questionnaire to this study is in the connection that will be found between students' perceptions of the socio-academic climate and of the teaching staff that is responsible for a tolerant atmosphere. In other words, the teaching practice, as perceived by students, may be a fundamental factor in students' sense of success in their academic studies.

In summary, what kind of teacher and teaching practices are best suited for students with HFA, or students with special needs? Such teachers adapt their methods to the goals they wish to achieve, to the abilities and reasoning of their students, to the context of the learning, etc. To integrate students with HFA into academic studies, lecturers should be informed about HFA and adapt specific teaching methods and practices that match their personalities and goals. Such a process takes time and entails self-reflection and self-observation. 


\section{The Theoretical Model}

Based on the review of literature, the starting point of the study is the assumption that academic institutions' support affects lecturers' academic climate and perceptions. The more intense and positive the institution's impact, the greater the potential for creating a tolerant atmosphere. At the same time, we believe that the institution has the greatest influence on lecturers' willingness to use advanced methods developed for students with special needs in an informed and beneficial manner to affect their integration.

The aims of the study are:

1. To examine the university's ability to contribute to the academic integration of students with HFA by influencing its teaching staff and students.

2. To identify the factors that have a positive impact on how lecturers promote the integration of students with HFA and their connection to the institution's support system.

The study included the above-mentioned variables that might also affect a tolerant atmosphere and the use of special developed methods, such as lecturers' involvement, "emotional response" to students with HFA, regular teaching methods, and familiarity with the field of HFA.

\section{Research questions}

1. Will the tolerant atmosphere be more positive when the academic institution is more involved and supportive?

2. Will lecturers make more use of special developed methods for students with HFA when the academic institution is more involved and supportive?

3. Will the tolerant atmosphere in the classroom be more positive and affect students with HFA when (a) the general lecturer involvement in class is higher; (b) when the lecturer has positive emotional responses toward students with HFA: when the lecturer is familiar with the field of HFA; when the lecturer is accustomed to use regularly in class new teaching methods?

Based on the aims of the research, the research questions, and the research literature, a model was developed to describe the influence of organizational support on tolerant atmosphere and lecturers' willingness to the use special developed methods with students with HFA.

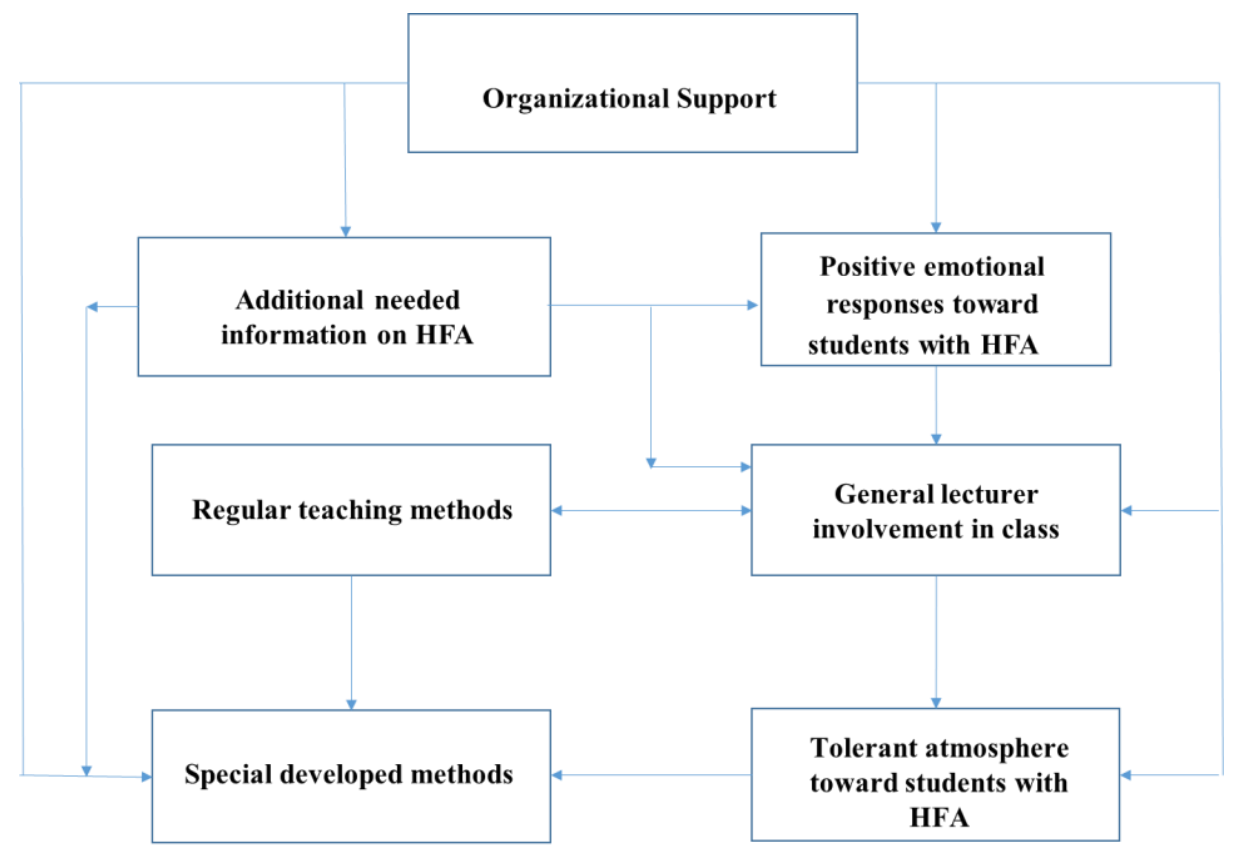

Figure 1. Model of the effect of organizational support on lecturers' attitudes 


\section{Methodology}

\subsection{The Study Sample}

All of the lecturers in Ariel University were approached by mail, and were asked to complete the study questionnaire. About 14\% of all lecturers participated: 48 (46\%) males and $55(54 \%)$ females of different ages and seniority in teaching. Eight lecturers (10\%) are between the ages of 26 and 35, 29 lecturers (30\%) are between the ages of 36 and 45, $33(32 \%)$ are between the ages of 46 and 55, and $30(28 \%)$ are between the ages of 56 and 80 . Twelve lecturers (12\%) have up to 5 years of teaching experience, $43(40 \%)$ have between 6 and 15 years of teaching experience, $31(30 \%)$ have between 15 and 25 years of teaching experience, and $17(18 \%)$ have between 26 and 40 years of teaching experience. Forty-four lecturers $(43 \%)$ teach in the Faculty of Humanities and Social Sciences, 23 (21\%) in the Faculty of Engineering, 21 (20\% in the Faculty of Health Sciences, and 15 (14\%) teach in the Faculty of Natural Sciences. Thirty-six lecturers (34\%) have a relative with a learning disability. Sixty-seven lecturers $(66 \%)$ have no academic experience-teaching students with disabilities. Sixty-four $(63 \%)$ lecturers have little or no knowledge about integrating students with HFA; $13(12 \%)$ have some knowledge, and 26 (25\%) have extensive knowledge. However, 45 (43\%) lecturers have experience teaching students with HFA and 58 (57\%) have no such experience. Only 40 lecturers (39\%) reported having extensive involvement with students with HFA while $63(61 \%)$ had little or no such involvement.

\subsection{Research Instruments}

Questionnaires were administered and a conceptual model was developed to describe the factors in the academic institution (lecturers) that affect the integration of students with HFA in their academic studies.

We used the following research scales in this study:

1. Familiarity with HFA - We used the personal detail questionnaire from a study by Sherman (2014) on higher education in Israel. The questionnaire includes items on familiarity with the field of HFA such as: Have you had experience teaching students with HFA? How extensive was your involvement? How extensive is your familiarity with the field of integrating students with HFA?

2. Organizational support, desire to acquire knowledge about HFA, special developed methods, tolerant atmosphere - We used a questionnaire on attitudes toward the integration of students with HFA in academic institutions, which is based on a research study on integration in youth movements (Vilchinsky \& Werner, 2007).

3. Emotions toward students with HFA - We used the Multidimensional Attitudes Scale developed by Findler, Vilchinsky \& Werner (2007). The questionnaire examines the emotional positive responses, and cognitive and behavioral components of attitudes toward people with disabilities. For the purpose of this study, we used the positive emotional responses section of this scale.

4. Lecturers' involvement, regular teaching methods - We used a social-academic climate questionnaire developed by Moss \& Insel (1974) and adapted the items in this research to the current sample.

\subsection{Statistical Procedures}

First, the validity of the scales was tested, using Cronbach's alpha coefficient of reliability to measure the reliability of the items found in the factor analysis. The coefficients are presented in Table 1 below. Only the 'organizational support' coefficient is slightly small.

Table 1. Reliability test of factors

\begin{tabular}{lcc}
\hline \multicolumn{1}{c}{ Factor } & No. of questions & Cronbach's alpha \\
\hline Organizational support & 10 & 71. \\
Positive emotional responses toward students with HFA & 5 & 83. \\
Regular teaching methods & 3 & 63. \\
General lecturer involvement in class & 7 & 70. \\
Additional needed information on HFA & 2 & 95. \\
Dependent variables & & \\
Tolerant atmosphere toward students with HFA & 3 & 89. \\
Special developed methods & 4 & 77. \\
\hline
\end{tabular}

After the validity test we performed analyses to identify the variables that affect the dependent variables, special developed method, and tolerant atmosphere, using the SPSS statistical package. First, we conducted stepwise 
multivariate regressions to examine the nature of the effect of organizational support on tolerant atmosphere and lecturers' willingness to use advanced teaching methods with students with HFA. Then, a Structural Equation Modeling of AMOS 24 was conducted to examine the associations to determine whether they are direct or indirect. The benefit of using multi-path modelling software is that although the results are similar to regression results, multi-path models enable a deeper analysis of the ties between dependent and independent variables and within the group of independent variables, including direct and indirect associations. This analysis graphically displays a set of equations for the overt and covert associations and assigns numerical values to them. The software makes it possible to examine the nature of the theoretical model using several evaluation factors: Chi-square test, based on the number of degrees of freedom for rejecting the null hypothesis that the actual result differs from the theoretical model; NFI and CFI (the closer these values are to 1, the better the fit of actual results to the theoretical model; RMSEA is used for more complex models.

The findings of these tests are presented below.

\subsection{Findings}

To answer the research questions about the best method for integrating students with HFA in academic studies we conducted two stepwise regressions with the dependent variables: a tolerant atmosphere or the special developed methods. The results are presented below in Table 2 .

Table 2. Regression to predict Tolerant atmosphere and Special developed methods

\begin{tabular}{|c|c|c|c|c|c|c|c|c|}
\hline \multirow{3}{*}{ Explanatory factors } & \multirow{2}{*}{\multicolumn{4}{|c|}{$\begin{array}{c}\begin{array}{c}\text { Tolerant atmosphere } \\
(\mathbf{N}=\mathbf{1 0 3})\end{array} \\
R^{2}=21 \% \\
\end{array}$}} & \multicolumn{4}{|c|}{$\begin{array}{c}\text { Special developed methods } \\
(\mathrm{N}=103)\end{array}$} \\
\hline & & & & & \multicolumn{4}{|c|}{$24 \%={ }^{2} R$} \\
\hline & $\beta$ & $B$ & Sig & $t$ & $\mathrm{~B}$ & $B$ & Sig & $T$ \\
\hline Organizational support and assistance & $.325 * *$ & .463 & .002 & 3.120 & $.241 *$ & .340 & .016 & 2.646 \\
\hline Additional needed information on HFA & $-.119 *$ & -.141 & .028 & -1.726 & - & - & - & - \\
\hline Special developed methods & $-.322 * *$ & -.313 & .002 & -3.127 & - & - & - & - \\
\hline Teaching methods & - & - & - & - & $.282 * *$ & .238 & .004 & 2.968 \\
\hline Tolerant atmosphere & - & - & - & - & $-.313 * *$ & -.314 & .002 & 2.464 \\
\hline
\end{tabular}

The results for 'Tolerant atmosphere' - Individual, institutional, and teaching factors explain $21 \%$ of the variance in tolerant atmosphere, $\mathrm{F}(3.86)=7.550$. The factor that contributes the most to explained variance is organizational support $(\beta=.325, p<.01)$. The factor that makes the second greatest contribution to explained variance is special developed methods $(\beta=-.322, p<.01)$ : The more special developed methods are used, the lower the tolerant atmosphere, and vice versa.

Another variable is the "additional needed information on HFA" $(\beta=-.119, p<.05)$ : The more a lecturer wishes to acquire more information about HFA, the less the lecturer supports a tolerant atmosphere, and vice versa. It appears that lecturers feel that if they have more knowledge of HFA then the classroom climate needs to be less tolerant.

The results for Special developed method - organizational support and lecturers' willingness to use regular teaching methods explain $24 \%$ of the variance of special developed methods, $F(3.89)=9.210$. The variable that contributes the most to the explained variance is a tolerant atmosphere $(\beta=-.313, p<.01)$ : The more tolerant the classroom climate, the less the need for special developed methods, and vice versa. The variable "regular teaching methods" makes the greatest positive contribution $(\beta=.282, p<.01)$ : The more the lecturer uses advanced teaching methods, the more he thinks that there is a need for advanced teaching methods for students with problems. Organizational support is another variable that contributes to lecturers' willingness to use special developed methods $(\beta=.241, p<.05)$ : The greater the organizational support, the greater lecturer's willingness to use special developed methods.

\section{Path Analysis}

In this study, we performed path analysis to examine the association between the dependent variables (special developed methods and tolerant atmosphere) and the independent variables. The results of the model show a high goodness of fit of the empirical data to the model $\left(\chi^{2}\right.$ value $\left.5.126(5), \chi^{2} / \mathrm{Df}=1.025, p=.401\right)$. All the relevant measures also showed acceptable levels of fit $(\mathrm{CFI}=.999$; NFI $=.975$; RMSEA $=.016)$ and the model was found to be valid.

The standard regression coefficients and their significance are presented in Figure 2. Table 3 below presents the 
direct and indirect correlations between the variables in the model.

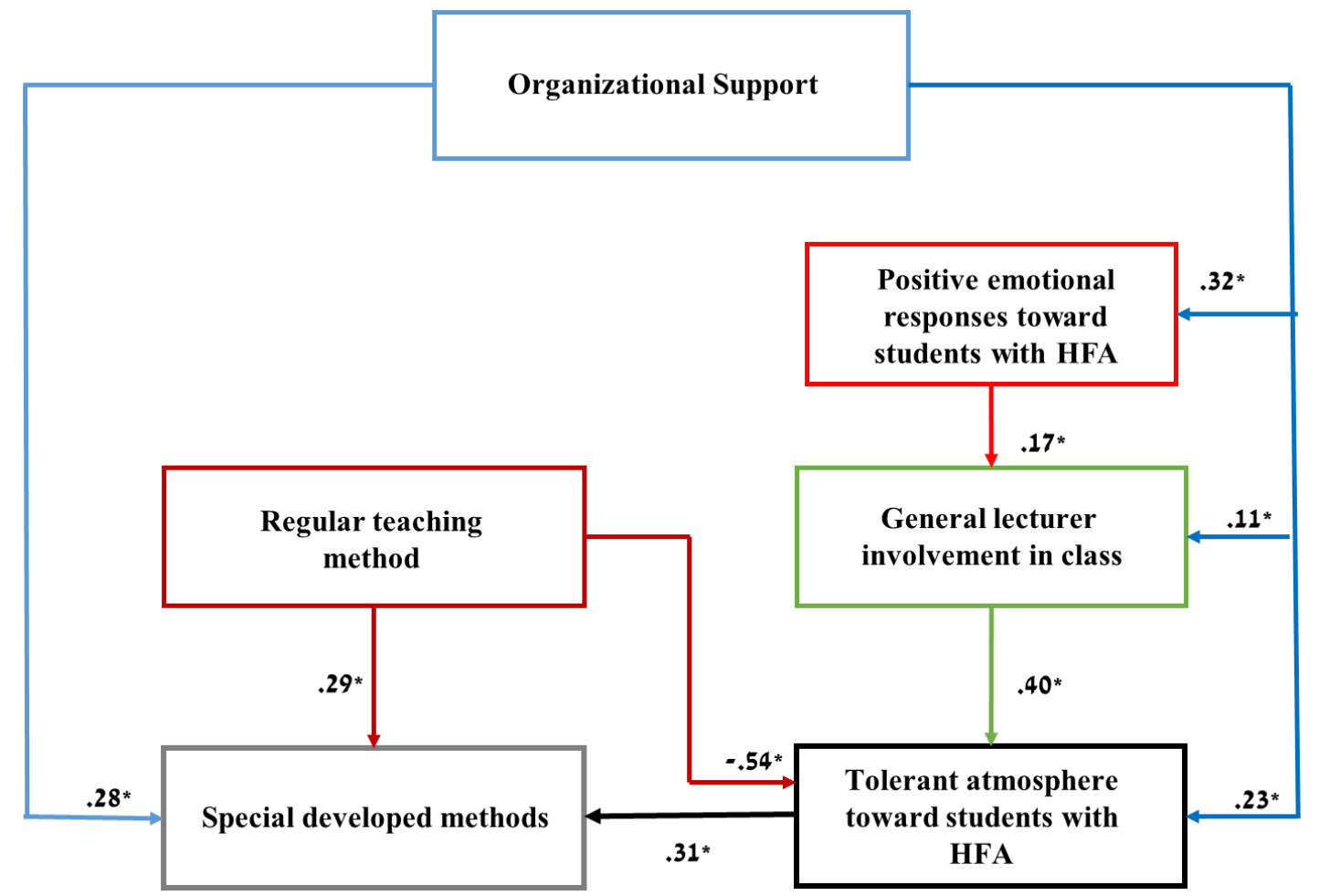

Figure 2. Results of the model - the effect of organizational support on lecturers' attitudes

Figure 2 indicates that organizational support has a direct positive effect on factors that facilitate integration - a tolerant atmosphere $(\beta=.23)$ and special developed methods $(\beta=.28)$. Organizational support has a low direct positive association with lecturers' involvement $(\beta=.11)$ and emotions toward students with HFA $(\beta=.32)$. No association was found between organizational support and teaching methods. General lecturers' involvement in class shows a low direct positive association with emotions toward students with HFA ( $\beta=.17)$. Lecturers' involvement also has a strong direct positive association with tolerant atmosphere $(\beta=.40)$. Regular teaching methods have a direct positive association with special developed methods $(\beta=.29)$. Furthermore, a negative association was found between regular teaching methods and tolerant atmosphere $(\beta=-.54)$ and between tolerant atmosphere and special developed methods. Familiarity with the field did not enter the model. Explained variance of tolerant atmosphere is $\mathrm{R}^{2}=17 \%$ and the explained variance of willingness to use advanced teaching methods is $\mathrm{R}^{2}=24 \%$.

Table 3. Direct and indirect correlations in the model

\begin{tabular}{|c|c|c|c|c|c|c|}
\hline \multirow[t]{2}{*}{ Effect } & \multicolumn{3}{|c|}{ Standardized Effect } & \multicolumn{3}{|c|}{ Regression Weights (direct) } \\
\hline & Total & Direct & Indirect & Estimate & C.R. & $P$ \\
\hline \multicolumn{7}{|l|}{ Athmosphere ot tolerance } \\
\hline Regular teaching methods & -.537 & -.537 & .000 & -.452 & -2.971 & $<.003$ \\
\hline General lecturer involvement in class & .398 & .398 & .000 & .539 & 2.171 & $<.030$ \\
\hline Organizational support & .295 & .230 & .065 & .326 & 2.332 & $<.020$ \\
\hline $\begin{array}{l}\text { Positive emotional responses toward } \\
\text { students with HFA }\end{array}$ & -.067 & .000 & -.067 & & & \\
\hline \multicolumn{7}{|l|}{ Special developed methods } \\
\hline Regular teaching methods & .454 & .287 & .168 & .252 & 3.200 & $<.001$ \\
\hline Tolerant atmosphere & -.312 & -.312 & .000 & -.327 & -3.268 & $<.001$ \\
\hline Organizational support & .184 & .276 & -.092 & .410 & 2.982 & $<.003$ \\
\hline General lecturer involvement in class & -.124 & .000 & -.124 & & & \\
\hline $\begin{array}{l}\text { Positive emotional responses } \\
\text { toward students with HFA }\end{array}$ & .021 & .000 & .021 & & & \\
\hline
\end{tabular}


Table 4. Additional correlations found

\begin{tabular}{|c|c|c|c|c|c|c|}
\hline \multirow[t]{2}{*}{ Effect } & \multicolumn{3}{|c|}{ Standardized Effect } & \multicolumn{3}{|c|}{ Regression Weights (direct) } \\
\hline & Total & Direct & Indirect & Estimate & C.R. & $P$ \\
\hline $\begin{array}{l}\text { Organizational support/positive } \\
\text { emotional responses toward students with HFA }\end{array}$ & .317 & .317 & .000 & -.382 & -3.303 & $<.000$ \\
\hline $\begin{array}{l}\text { Emotions toward students with } \\
\text { HFA/General lecturer involvement in class }\end{array}$ & -.168 & -.168 & .000 & -.146 & -3.264 & $<.001$ \\
\hline $\begin{array}{l}\text { Organizational support/General } \\
\text { lecturer involvement in class }\end{array}$ & .164 & 111 & .053 & .116 & 2.117 & $<.034$ \\
\hline
\end{tabular}

Furthermore, an effect of emotions toward students with HFA was found to have a direct and indirect association of .317 and an association of .164 of lecturers' involvement on organizational support. A negative effect was found of lecturers' involvement on emotions toward students with HFA.

\section{Summary and Discussion}

The results of this study show, as expected, that the institutional support provided by the university is an important factor that influences instructors' preferred method for integrating students with HFA, either a tolerant atmosphere or specially developed teaching methods. Lecturers' positive emotional responses and desire to be familiar and involved with HFA students influence lecturers' ability to provide effective support to students with HFA. Instructors believe that, together with other tools, the best way to help students with HFA is to ensure that organizational support is in place. Lecturers believe that their involvement in what happens in the classroom positively affects a tolerant climate. To get to know their students and their knowledge and needs, lecturers need to speak to students and become involved in their learning.

Organization support is also an important factor influencing the use of specially developed methods, but the most important factor that influences lecturers' use of special teaching methods is lecturers' experience with the use regular teaching methods.

The most surprising result is the negative relation found between the two teaching methods studied in the research for integration of students with HFA. The findings may be explained by differences in lecturers' qualifications. Lecturers who rely more strongly on their emotional attitudes tend to use a tolerant atmosphere in class, but lecturers who rely more strongly on their cognitive attitudes in their regular teaching, prefer to use special methods developed for these students. There is no need for a lecturer to use both systems. A tolerant classroom climate develops understanding of others and a desire to provide support to others. That is to say, you don't have to be an educator to create a positive atmosphere; it is more important to be tolerant. The use of special teaching methods does not affect the classroom climate, which remains unchanged for the other students.

In sum, organizational support plays an important role in the integration of students with HFA by creating a tolerant classroom climate and by helping lecturers select and employ appropriate methods of assessment for students with HFA. Ultimately, a supportive, tolerant atmosphere, positive ties with the lecturer, and appropriate teaching practices, with organizational support on all sides, enables students with HFA to realize their academic potential.

This study presents the perspective of lecturers yet it is important to adopt a holistic approach to a program designed to promote the integration of students with HFA, which includes the involvement of the following parties: the organization, the teaching staff, and the student body, including teaching assistants. Efforts should be invested to ensure a holistic perspective, meaningful learning in heterogeneous classes, and a tolerant atmosphere on campus in order to help individuals with disabilities integrate into society (Reiter \& Schalock, 2008). Academic institutions have three important functions: research, teaching, and community service. Academic institutions should support the goal of integration, and endorse one or both methods of achieving this goal. With respect to community service, the most important thing to have is a desire to accept students with special needs. Academic institutions should also adopt a holistic approach to support students with HFA that includes intensive support, activities to enhance students and lecturers' awareness of autism and understand the needs of students with HFA, and develop social and academic programs. Furthermore, academic institutions should be aware that a supportive social-academic climate, lecturers' involvement in students' learning, and the tools used by lecturers are significant factors that affect all students, and not only students with special needs (Ponomareva, Davidovitch, \& Shapira, 2016). 


\section{References}

Admiraal, W., \& Lockhorst, D. (2012). An Expert Study of a Descriptive Model of Teacher Communities. Learning Environments Research, 15(3), 345-361.

Avisar, G. (2010). Containment and accessibility: On planning programs and curricula for students with disabilities. Tel Aviv: Mofet Institution [Hebrew]

Bandura, A. (1997). Self-efficacy: Toward a unifying theory of behavior change. Psychological Review, 84, 191-215. https://doi.org/10.1037/0033-295X.84.2.191

Berry, J. W. (1991).Understanding and managing multiculturalism. Psychology and Developing Societies, 3, 17-49. https://doi.org/10.1177/097133369100300103

Darling-Hammond, L., \& Bransford, J. (2007). Preparing Teachers for a Changing World: What Teachers Should Learn and Be Able to Do. Jossey-Bass, August 2007, 640 pp.

Davidovitch, N. (2005). Higher Education at a Crossroads: Trends in the Development of Regional Colleges and their Implications for the Higher Education System in Israel. Teligraph-Nahir Publishing. ISSN 965-7376-01-7. (In Hebrew). 338 pp.

Davidovitch, N., \& Casakin, H. (2015).Academic social climate - A key aspect in architectural studies. International Journal of Art \& Design Education, 34(2), 237-248. https://doi.org/10.1111/jade.12009

Davidovitch, N., Ponomareva, E., \& Shapiro, Y. (2017).Attitudes of students and teaching staff regarding the integration of high functioning autistic students in the higher education system in Israel. International Journal of Child Health and Human Development, 10(1).11-16.

Davidovitch, N., Schacham, S. E., \& Margalit, D. (2012). Coping with learning disabilities in academic institutions - A case study. International Journal on Disability and Human Development, 11(1), 45-49.

Delfos, M. F. (2005). A strange world: Autism, Asperger's syndrome, and PDD-NOS: A guide for parents, partners, professional carers, and people with HFAs. London and Philadelphia: Jessica Kingsley.

Findler, L., Vilchinsky, N., \& Werner, S. (2007). The Multidimensional Attitudes Scale toward Persons with Disabilities (MAS). Rehabilitation Counseling Bulletin, 50, 166-176.

Gurtin, P., Dey, E. L., Hurtado, S., \& Gurtin, G. (2002).Diversity and higher education: Theory and impact on educational outcomes. Harvard Educational Review, 72(3), 330-366. https://doi.org/10.17763/haer.72.3.01151786u134n051

Happe, F. G. E. (1991).The autobiographical writings of three Asperger syndrome adult: Problems of interpretation and implication for theory. In U. Frith (Ed.), Autism and Asperger Syndrome (pp. 28-65). Cambridge: Cambridge University Press. https://doi.org/10.1017/CBO9780511526770.007

Hativa, N., \& Goodyear, P. (2002). Research on teacher thinking, beliefs and knowledge in higher education: Foundations, status and prospects. In N. Hativa snf P. Goodyear (Eds.), Teacher thinking, beliefs and knowledge in higher education (pp. 335-359). Dordrecht, the Netherlands. https://doi.org/10.1007/978-94-010-0593-7_15

Hendrickx, S. (2009). Asperger syndrome and employment: What people with Asperger syndrome really want? London and Philadelphia: Jessica Kingsley.

Knotta, F., \& Taylora, A. (2014). Life at university with Asperger syndrome: a comparison of student and staff perspectives. International Journal of Inclusive Education, 18(4), 411-426. https://doi.org/10.1080/13603116.2013.781236

Levinson, S. (1980). Effect of Personality and Environmental Factors on Adult Creative Behavior. $\mathrm{PhD}$ dissertation for the degree of doctor of philosophy, Department of Psychology, Tel Aviv University.

MacLeoda, A., \&Greena, S. (2009). Beyond the books: Case study of a collaborative and holistic support model for university students with Asperger syndrome. Studies in Higher Education, 34(6), 631-646. https://doi.org/10.1080/03075070802590643

Moos, R. H., \& Insel, P. M. (1974). Psychological environments: Expanding the scope of human ecology. American Psychologist, 29(3), 179-188. https://doi.org/10.1037/h0035994

Narasingharao, K., Pradhan, B., \& Navaneetham, J. (2017). Efficacy of structured yoga intervention for sleep, gastrointestinal and behavior problems of HFA children: An exploratory study. journal of clinical and 
diagnostic research. Journal of Clinical and Diagnostic Research, 11(3), VC01.

Oplatka, I. (2007). Managing Emotions in Teaching: Toward an Understanding of Emotion Displays and Caring as Nonprescribed Role Elements. Teachers College Record, 109, 1374-1400.

Palmer, A. (2006). Realizing the college dream with autism or Asperger syndrome: A parent's guide to student success. London; Philadelphia: Jessica Kingsley.

Ponomareva, E., Davidovitch, N., \& Shapira, Y. (2016). How do academic institutions integrate students with high-functioning autism? In R. Parsons (Ed), Learning disabilities: Assessment, management and challenges (pp. 183-196). New York, Nova Science.

Reiter, S., \& Schalock, R. L. (2008).Applying the concept of quality of life to Israeli Special Education programs: A national curriculum for enhanced autonomy in students with special needs. International Journal of Rehabilitation Research, 3, 113-121. https://doi.org/10.1097/MRR.0b013e3282f45201

Rich, Y., Lev, S., \& Fischer, S. (2000). Extending the concept and assessment of teacher efficacy. Bar-Ilan University.

Sherman, K. (2014). Cognitive interviews guide design of a new CAM patient expectations questionnaire. Complementary and Alternative Medicine: The official journal of the International Society for Complementary Medicine Research (ISCMR). https://doi.org/10.1186/1472-6882-14-39

UN General Assembly. (2007). Convention on the Rights of Persons with Disabilities: Resolution. Available from http://www.unhcr.org/refworld/docid/45f973632.html.

Vaandrager, L., \& Koelen, M. (2013). Salutogenesis in the Workplace: Building General Resistance Resources and Sense of Coherence (pp. 77-89). Georg F. BauerGregor J. Jenny: Salutogenic organizations and change. The concepts behind organizational health intervention research.

Volkmar, F. R. (Ed.) (2013). Encyclopedia of autism spectrum disorders. New York: Springer. https://doi.org/10.1007/978-1-4419-1698-3

Ward, T., \& Stewart, C. (2008). Putting human rights into practice with people with an intellectual disability. Journal of Developmental and Physical Disabilities, 20, 297-311. https://doi.org/10.1007/s10882-008-9098-4

\section{Copyrights}

Copyright for this article is retained by the author(s), with first publication rights granted to the journal.

This is an open-access article distributed under the terms and conditions of the Creative Commons Attribution license (http://creativecommons.org/licenses/by/4.0/). 